\title{
COMPARAÇÃO ENTRE TRÊS BIOPROCESSOS PARA A PRODUÇÃO DE ENZIMAS PROTEOLÍTICAS UTILIZANDO RESÍDUOS AGROINDUSTRIAIS
}

\section{COMPARISON BETWEEN THREE BIOPROCESS FOR PROTEOLYTIC ENZYMES PRODUCTION USING AGROINDUSTRIAL WASTES}

\author{
Anne Caroline Defranceschi Oliveira ${ }^{1}$; Felipe Miguel Farion Watanabe ${ }^{2}$; José Viriato Coelho Vargas ${ }^{3}$; André \\ Bellin Mariano ${ }^{4}$; Maria Luiza Fernandes Rodrigues ${ }^{5}$ \\ ${ }^{1-4}$ Universidade Federal do Paraná - UFPR - Curitiba - Brasil annewcaroline@ hotmail.com \\ ${ }^{5}$ Universidade Tuiuti do Paraná - UTP - Curitiba - Brasil mlmfernandes@ hotmail.com
}

\begin{abstract}
Resumo
As proteases são enzimas capazes de clivar as ligações peptídicas de proteínas e dentro das enzimas são as que mais possuem emprego industrial. $O$ objetivo deste trabalho foi comparar três diferentes bioprocessos para a produção de proteases. Foram testados uma fermentação submersa (FSm) e dois tipos de fermentação no estado sólido, uma com suporte natural (FES) e outra com suporte sintético (PUF). A FES utilizando o suporte natural bagaço de cana de açúcar apresentou maior produtividade da enzima e em menor tempo. Este fato pode ser explicado pela grande adaptação da cepa fúngica utilizada ao ambiente fornecido por este processo. Nos ensaios de caracterização, a enzima apresentou pH e temperatura ótimos em 6,5 e $30^{\circ} \mathrm{C}$, respectivamente. A protease também apresentou boa resistência aos íons, apresentando ativação na presença de lítio $e$ EDTA. É possível concluir que o processo de FES é uma ótima opção para a produção de metabólitos fúngicos de interesse industrial.
\end{abstract}

Palavras-chave: enzimas proteolíticas; fermentação; resíduos agroindustriais.

\section{Introdução}

Proteases são enzimas capazes de clivar as ligações peptídicas de proteínas e peptídeos. São classificadas como classe 3 das enzimas, as hidrolases, e sua subclasse é a (EC 3.4) das hidrolases que rompem as ligações peptídicas, sendo enzimas amplamente aplicadas industrialmente na degradação de proteínas e também na síntese de peptídeos (GERMANO, 2000; CABRAL et al., 2004; PILLAI et al., 2011).

As enzimas proteolíticas constituem a maior família de enzimas utilizadas industrialmente no mundo todo, movimentando a economia deste setor ativamente (HADDAR et al., 2010; PILLAI et al., 2011). As proteases foram primeiramente obtidas de animais (como é o caso da renina e da tripsina) ou vegetais (como no caso da bromelina, extraída do abacaxi) (LADEIRA et al., 2010). As 
proteases obtidas de micro-organismos são utilizadas na indústria devido a algumas características peculiares, como: a fácil obtenção (principalmente as fúngicas, pois são extracelulares, portanto de fácil recuperação); baixo custo, pois como substratos para sua produção podem ser usados resíduos agroindústrias; e características de interesse industrial como a termoestabilidade (GERMANO et al., 2003; DIVACAR et al., 2010). Os micro-organismos em geral podem ser bons produtores de proteases, uma vez que possuem uma grande diversidade bioquímica e também uma fácil manipulação genética (GERMANO, 2000; NASCIMENTO e MARTINS, 2006; KASANA et al., 2011).

As proteases são enzimas de caráter indutivo, ou seja, precisam de um indutor para serem secretadas pelos micro-organismos. Outro parâmetro de suma importância é fornecer um ambiente propício ao crescimento microbiano (GERMANO, 2000; AGRAWAL et al., 2004).

Cada micro-organismo possui características específicas tanto nutricionais como ambientais. As características do meio de propagação são de suma importância para uma boa secreção de metabólitos, pois quanto mais rápido o micro-organismo se adaptar ao meio, mais rápida e eficiente será a secreção do metabólito de interesse (SILVA, 2002; FERNANDES, 2006).

Existem dois tipos básicos de processos fermentativos para obtenção de metabólitos: a fermentação no estado sólido (FES) e a fermentação submersa (FSm). A FES baseia-se no crescimento dos micro-organismos em substratos sólidos na ausência (ou quase) de água livre (FERNANDES et al., 2007), sendo um processo microbiano que geralmente ocorre na superfície dos materiais sólidos que tem capacidade de absorver água, podendo ou não conter nutrientes solúveis (SILVA, 2002). A absorção de agua é essencial para este processo, e para isso é necessário o emprego de substratos fibrosos, que podem ou não fornecer nutrientes para o micro-organismo (SOCCOL e VANDENBERGHE, 2003). Dois tipos de suportes podem ser empregados: os naturais que podem ser resíduos agroindustriais como o bagaço de cana de açúcar e a casca de arroz, que possuem caráter fibroso, devido a cadeias poliméricas, geralmente não metabolizáveis pelos microorganismos; e os sintéticos, que são substâncias geralmente poliméricas capazes de reter água em sua estrutura, como é o caso da espuma de poliuretano (FERNANDES, 2006; SHINGANIA et al., 2009; FARINAS et al., 2011).

A fermentação submersa (FSm) é um processo que disponibiliza os nutrientes para o microorganismo em meio líquido. Nutrientes como peptonas, açúcares e substâncias complexas (vitaminas e íons) são dissolvidos em água ou mesmo soluções tampões. Essas fermentações devem ser mantidas em agitação constante para ideal aeração e disponibilidade de nutrientes (FERNANDES et al., 2007; FARINAS et al., 2011).

O objetivo deste trabalho foi comparar a produção de enzimas proteolíticas pelos processos de fermentação submersa e fermentação no estado sólido, com suporte natural e sintético. 


\section{Material e Métodos}

\section{Seleção de cepas proteolíticas}

As cepas proteolíticas foram selecionadas em placa de Petri, conforme descrito por Germano (2000) com algumas modificações, em meio contendo leite em pó desnatado $2 \%$ como única fonte de carbono e ágar $1,5 \%$. As cepas foram inoculadas por picada e incubadas a $28{ }^{\circ} \mathrm{C}$ por $72 \mathrm{~h}$. A atividade proteolítica foi observada pela formação de halo transparente ao redor da colônia.

\section{Fermentação}

Foram testados três modelos de fermentação para a produção de enzimas proteolíticas, as quais possuíam a mesma fonte de nutriente, apenas variando as condições físicas do meio.

As fermentações foram conduzidas em frascos Erlenmeyers de $125 \mathrm{~mL}$, contendo $3 \mathrm{~g}$ de resíduo levedo de cerveja como fonte de nutriente, sendo a umidade conferida por tampão fosfato $100 \mathrm{mM}$ em pH 7,0, sendo cada meio composto por:

FES: a fermentação no estado sólido foi realizada com $2 \mathrm{~g}$ de bagaço de cana de açúcar e 300\% de umidade. O bagaço de cana de açúcar foi fervido 3 vezes, por 10 minutos em água destilada para retirar os resíduos de açúcares do material, de modo que este apresentasse apenas aplicação como suporte;

* PUF: outro modelo de fermentação no estado sólido, porém o suporte usado foi a espuma de poliuretano (PUF). Cada Erlenmeyer continha $1 \mathrm{~g}$ de cubos de PUF de aproximadamente 1 $\mathrm{cm}^{3}$, e a umidade foi obtida adicionando-se $10 \mathrm{~mL}$ de tampão;

FSm: a fermentação submersa foi realizada apenas utilizando-se o nutriente e $30 \mathrm{~mL}$ de tampão.

Todas as fermentações foram incubadas em Shaker a $28^{\circ} \mathrm{C}$ e $150 \mathrm{rpm}$, sendo amostras retiradas a cada 24 h durante $96 \mathrm{~h}$.

O extrato enzimático foi obtido adicionando-se solução de $\mathrm{NaCl} 1 \%$ ao volume final de 50 mL em cada fermentação e agitado em Shaker por aproximadamente 30 minutos. Após agitação o extrato foi filtrado em tecido, sob pressão mecânica e centrifugado a 2000 rpm por 10 min, para obter o extrato bruto livre de células.

\section{Ensaio enzimático}

A dosagem da atividade enzimática foi realizada pelo método descrito por Secades e Guijarro (1999). Para o ensaio, foram adicionados $120 \mu \mathrm{L}$ de amostra a $480 \mu \mathrm{L}$ de solução de azocaseína $1 \%$, em $\mathrm{pH} 7,0$. Incubou-se por $30 \mathrm{~min}$ a $30^{\circ} \mathrm{C}$. A reação foi paralisada por $600 \mu \mathrm{L}$ de 
ácido tricloroacético (TCA) 10\%. Centrifugou-se a $2000 \mathrm{rpm}$ por $10 \mathrm{~min}$. Do sobrenadante foram retirados $800 \mu \mathrm{L}$ e adicionados $200 \mu \mathrm{L}$ de $\mathrm{NaOH}$ 1,8 N. A absorbância foi lida a $420 \mathrm{~nm}$.

Uma unidade de atividade proteolítica foi definida como a quantidade de enzima necessária para aumentar 0,01 na absorbância à $420 \mathrm{~nm}$ nas condições de tempo e temperatura de incubação do

teste, sendo o resultado expresso em $\mathrm{U} \mathrm{mL}^{-1}$, e posteriormente calculado para ser expresso em Unidades totais $(\mathrm{U})$.

\section{Caracterização da enzima}

As enzimas foram caracterizadas conforme descrito por Thys (2004) e Giongo (2006), quanto ao seu pH e temperatura ótima, e a influência de íons.

Para avaliar o pH ótimo, o ensaio enzimático foi conduzido conforme descrito anteriormente, porém, a azocaseína foi solubilizada em tampões de diferentes valores de pH: 5,5 e 6 (tampão acetato), 6,5, 7 e 7,5 (tampão fosfato) e 8 e 8,5 (tampão Tris-HCl).

Para avaliar a temperatura ótima, o ensaio enzimático foi realizado conforme descrito anteriormente, porém a incubação foi realizada em diferentes temperaturas: 10, 20, 30, 37, 45 e 55 ${ }^{\circ} \mathrm{C}$.

A influência de diferentes íons foi avaliada incubando-se os extratos enzimáticos em soluções contendo: $\mathrm{ZnCl}_{2}, \mathrm{CaCl}_{2}, \mathrm{CoCl}_{2}, \mathrm{FeCl}_{3}, \mathrm{MnCl}_{2}, \mathrm{LiCl}$ e o quelante EDTA nas concentrações finais de 1 e $10 \mathrm{mM}$, por 10 minutos. Após a incubação foi realizado o ensaio enzimático conforme descrito anteriormente.

\section{Resultados e Discussão}

\section{Seleção da cepa proteolítica}

Foram testadas 30 cepas de fungos endofíticos isolados da erva-mate para avaliar sua capacidade de produção de enzimas proteolíticas. Destas 30 cepas, 19 (63\%) apresentaram atividade proteolítica (Figura 1).

A escolha da cepa para os ensaios de produção da enzima baseou-se na observação visual da formação do halo ao redor da colônia, característica observada por Thys (2004). A cepa escolhida foi caracterizada por microcultivo como Penicillium $\mathrm{sp}$.

Para a produção da enzima foram testadas três diferentes condições ambientais: uma líquida e duas sólidas, uma conferida por bagaço de cana-de-açúcar e a outra por espuma de poliuretano. 
Figura 1 - Halo de proteólise formada pela cepa de Penicillium sp.

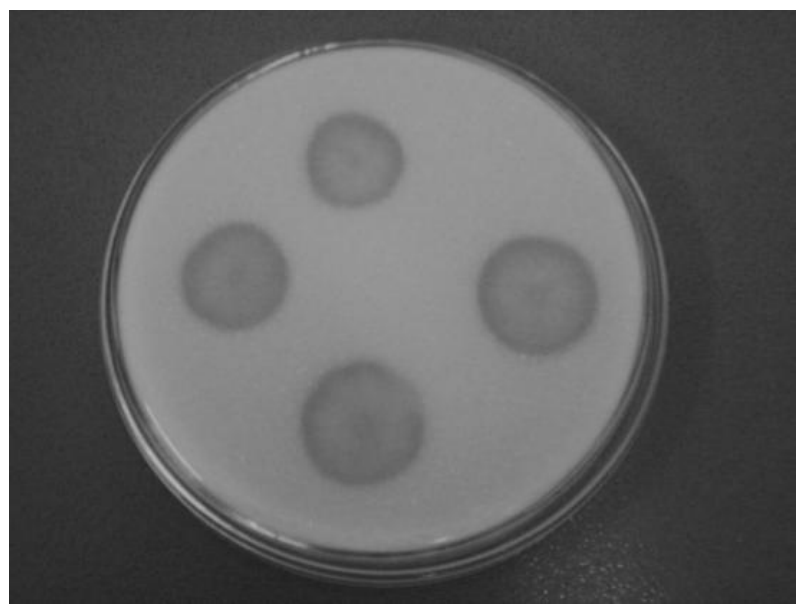

Fonte: O AUTOR

\section{Produção da enzima}

Na figura 2 é possível observar a comparação entre os meios fornecidos.

Figura 2 - Comparação da produção de enzimas proteolíticas em função do tempo nos bioprocessos de: fermentação no estado sólido natural (FES), fermentação no estado sólido em suporte inerte de poliuretano (PUF) e fermentação submersa (FSm)

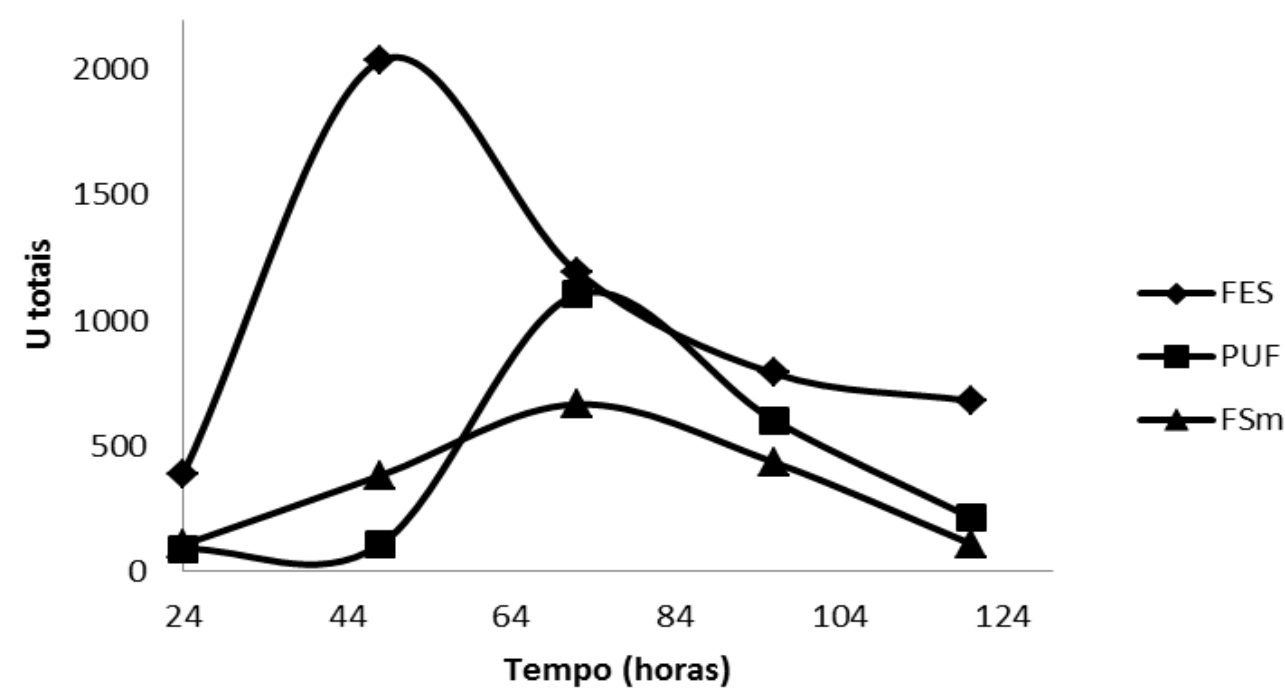

Como pode ser observado na figura 2, a maior produção da enzima ocorreu em $48 \mathrm{~h}$ de fermentação no estado sólido, com o suporte natural bagaço de cana-de-açúcar (2035 U totais). Nos outros modelos de fermentação, os picos máximos foram de 1104 U totais na fermentação no estado sólido com o suporte inerte de espuma de poliuretano e 666 U totais em fermentação submersa, ambos em $96 \mathrm{~h}$. 
Todos os meios forneciam a mesma quantidade de nutrientes além das mesmas condições de cultivo ( $\mathrm{pH}$ 7,0 e temperatura de $30^{\circ} \mathrm{C}$ ), a única variante do meio era o suporte que caracterizaria a fermentação.

A fermentação submersa apresentou a menor atividade proteolítica. Isto pode ser explicado pelo fato de neste trabalho ter sido utilizada uma cepa fúngica. Estas possuem características diferenciadas das bactérias, que se adaptam a este meio facilmente. Os fungos geralmente necessitam de um suporte sólido, ao qual se aderem para crescimento (MAHANTA et al., 2008; SILVA et al., 2009).

O suporte natural bagaço de cana-de-açúcar apresentou melhor desempenho do que o suporte sintético espuma de poliuretano. A atividade observada em PUF em 96 h é bastante significativa, porém este resultado demonstra que a cepa levou bem mais tempo para se adaptar a este meio em relação ao bagaço de cana. O PUF apresenta uma absorção de água bem menor que o observado no bagaço de cana de açúcar, um dos motivos pela menor adaptação da cepa ao meio (JOHN et al., 2007).

O meio FES apresentou a maior atividade, e com pico em menor tempo, em $48 \mathrm{~h}$. Isso mostra que a cepa se adaptou ao meio mais rapidamente, e logo começou a secretar o metabólito de interesse, devido a alta presença de indutor. Já é descrito que os fungos necessitam de ambientes sólidos e úmidos para o seu desenvolvimento, e a FES representa uma simulação quase que perfeita do habitat destes organismos (SILVA et al., 2009).

\section{Caracterização da enzima}

Para a caracterização da enzima proteolítica produzida foram avaliados três parâmetros: $\mathrm{pH}$, temperatura e influência de íons na atividade.

As atividades residuais apresentadas são compatíveis com as observadas na literatura para enzimas fúngicas. As enzimas geralmente apresentam características bioquímicas semelhantes as dos organismos que as secretam, que neste caso, por se tratarem de enzimas fúngicas apresentam temperatura ótima próxima da temperatura ambiente que estes organismos são encontrados $\left(30^{\circ} \mathrm{C}\right)$ e $\mathrm{pH}$ próximo da neutralidade, faixa descrita como a preferencial para estes micro-organismos (GERMANO et al., 2003).

A temperatura ótima da enzima pode ser observada em $30^{\circ} \mathrm{C}$, e seu pH ótimo em 6,5 , como pode ser observado na figura 3. 
Figura 3 - (A) Atividade residual da enzima em função do pH, (B) Atividade residual da enzima em função da temperatura

\section{(A)}

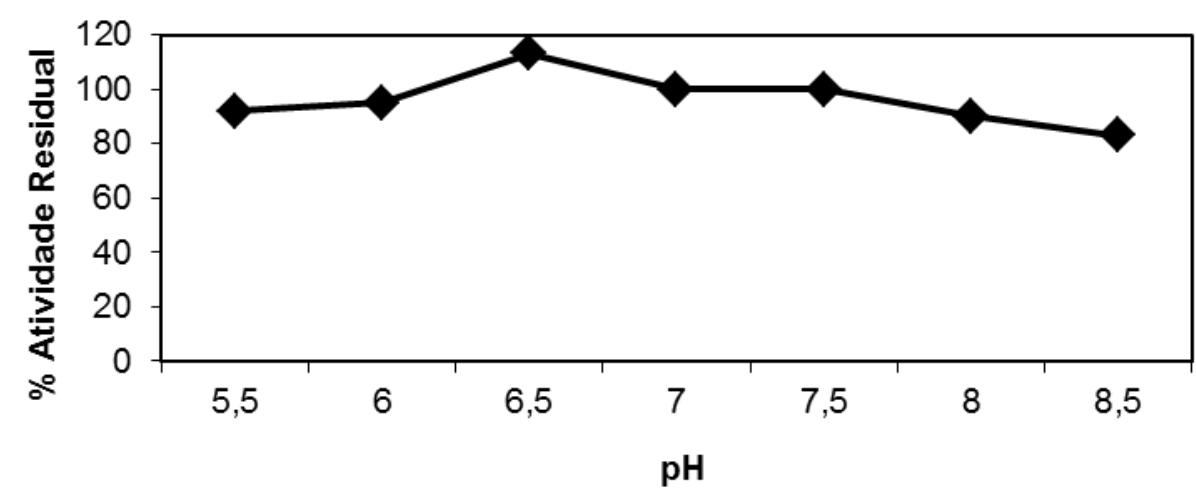

(B)

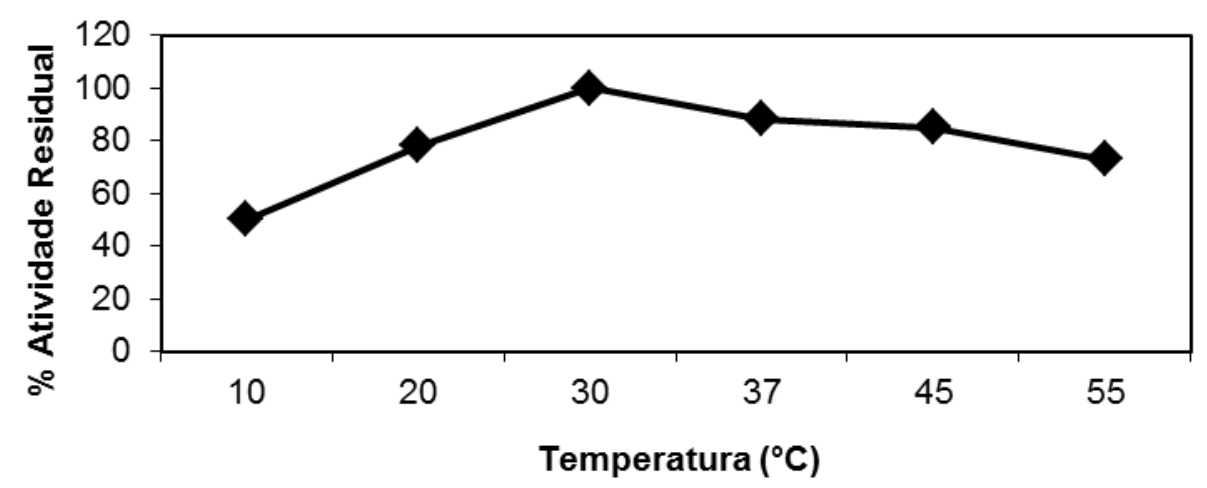

Neste ensaio de caracterização também foi avaliado a influência de íons, e do quelante EDTA na atividade desta enzima, como pode ser observado na figura 4.

Figura 4 - Atividade residual da enzima em função da adição de íons e do quelante EDTA na concentração de 1 e 10 $\mathrm{mM}$

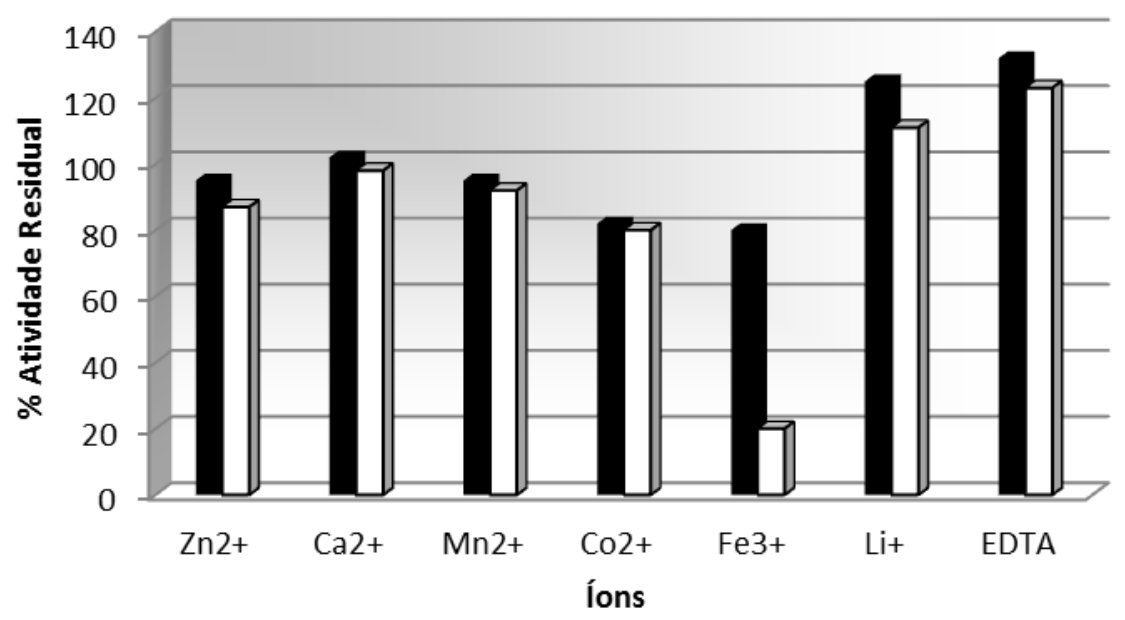


A enzima proteolítica produzida se mostrou bastante estável a presença de íons em ambas as concentrações, perdendo grande porcentagem da atividade apenas na presença de ferro. A enzima apresentou ativação na presença de cloreto de lítio, apresentado ganho de $25 \%$ (1 mM) e $11 \%$ (10 $\mathrm{mM}$ ) de aumento na atividade na presença deste íon. Porém, o mais pronunciado aumento de atividade ocorreu com a adição de EDTA.

Este resultado pode ser justificado pelo fato do EDTA quelar íons pesados, geralmente nocivos à atividade enzimática, como pôde ser observado no caso do ferro para a enzima produzida, bloqueando alguns dos agentes que podem afetar a atividade desta enzima.

\title{
4 Conclusões
}

Com os resultados obtidos é possível concluir que a fermentação no estado sólido utilizando resíduos agroindustriais, como o levedo de cerveja e o bagaço de cana, é uma opção vantajosa e barata para a produção de metabólitos de interesse industrial, como as enzimas proteolíticas.

A FES por apresentar características favoráveis ao desenvolvimento de linhagens fúngicas pode ser amplamente explorada para a produção de metabólitos por este tipo de micro-organismo, pois além de ser economicamente viável, também tem influência no impacto ambiental, pois os resíduos da agroindústria que seriam descartados no ambiente podem ser utilizados como fontes de nutrientes para a produção de biomoléculas de interesse industrial, como é o caso das enzimas.

\section{Agradecimentos}

Agradecemos ao CNPq pelo apoio financeiro, a Universidade Tuiti do Paraná por ceder os laboratórios de Microbiologia e Bioquímica e a Capes pela concessão das bolsas de mestrado.

\begin{abstract}
Proteases are enzymes capable of cleaving peptide bonds of proteins and, among all enzymes, they have the largest industrial employment. The objective of this study was to compare three different bioprocesses for the production of proteases. We tested a submerged fermentation $(\mathrm{SmF})$ and two types of solid-state fermentation, with a natural support (SSF) and the other with synthetic support (PUF). The natural support SSF using sugarcane bagasse showed higher productivity of the enzyme in a shorter time. This fact can be explained by the great adaptation of the used fungical strain to the environment provided by this process. In the characterization tests, the enzyme had $\mathrm{pH}$ and temperature optimum values of 6.5 and $30^{\circ} \mathrm{C}$, respectively. The protease also showed good resistance to ions, with activation under presence of EDTA and lithium. It can be concluded that the SSF process is a great option for the production of fungical metabolites with industrial interest.
\end{abstract}

Key-words: proteolytic enzymes; fermentation; agroindustrial waste. 


\section{Referências}

AGRAWAL, D.; PATINAR, P.; BANERJEE, T.; PATIL, S. Production of alkaline protease by Penicillium sp. under SSF conditions and its application to soy protein hydrolysis. Process Biochemistry, v. 39, n. 8, p. 977-981, 2004. http://dx.doi.org/10.1016/S0032-9592(03)00212-7

CABRAL, C. M.; CHERQUI, A.; PEREIRA, A.; SIMÕES, N., Purification and characterization of two distincts metalloproteases secreted by the entomopathogenic bacterium Photorhabdus sp. strain Az29. Applied Environmental Microbiology., v. 70, n. 7, p. 3831-3838, 2004. http://dx.doi.org/10.1128/AEM.70.7.3831-3838.2004

DIVAKAR, K.; PRIYA, J. D. A.; GAUTAM, P. Purification and characterization of thermostable organic solventstable protease from Aeromonas veronii PG01. Journal Molecular Catalysis B: Enzymatic, v. 311,n. 3, p. 311-318, 2010. http://dx.doi.org/10.1016/j.molcatb.2010.06.008

FARINAS, C. S.; SCARPELINI, L. M.; MIRANDA, E. A.; BERTUCCI NETO, V. Evaluation of operational parameters on the precipitation of endoglucanase and xylanase produced by solid state fermentation of Aspergillus niger. Brazilian Journal Chemical Engineering, v. 28, n. 1, p. 17-26, 2011. http://dx.doi.org/10.1590/S010466322011000100003

FERNANDES, M. L. M. Produção de lipases por fermentação no estado sólido e sua utilização em biocatálise. Curitiba, 130f. Tese (Doutorado em Química) - Setor de Ciências Exatas - Universidade Federal do Paraná.

FERNANDES, M. L. M.; SAAD, E. B.; MEIRA, J. A.; RAMOS, L. P.; MITCHELL, D. A.; KRIEGER, N. Esterification and transesterification reactions catalysed by addition of fermented solids to organic reaction media. Journal Molecular Catalysis B: Enzymatic, $\quad$ v. $\quad 44, \quad$ n. $\quad 1, \quad$ p. $\quad 8-13, \quad 2007$. http://dx.doi.org/10.1016/j.molcatb.2006.08.004

GERMANO, S. Desenvolvimento de bioprocessos para produção, caracterização e purificação de proteases de Penicillium sp. por fermentação no estado sólido. Curitiba, 2000. 142f. Tese (Doutorado em Processos Biotecnológicos) - Setor de Tecnologia - Universidade Federal do Paraná.

GERMANO, S.; PANDEY, A.; OSAKU, C. A.; ROCHA, S. N.; SOCCOL, C. R. Characterization and stability of proteases from Penicillium sp. produced by solid-state fermentation. Enzyme and Microbial Technology, v. 32, n. 2, p. 246-251, 2003. http://dx.doi.org/10.1016/S0141-0229(02)00283-1

GIONGO, J. L. Caracterização e aplicação de proteases produzidas por linhagens de Bacillus sp. Porto Alegre, 2006. 95f. Dissertação (Mestrado em Microbiologia Agrícola e do Ambiente) - Faculdade de Agronomia Universidade Federal do Rio Grande do Sul.

HADDAR, A.; FAKHFAKH-ZOUARI, N.; HMIDET, N.; NASRI, F. F. M.; KAMOUN, A. S. Low-cost fermentation medium for alkaline protease production by Bacillus mojavensis A21 using hulled grain of wheat and sardinella peptone, Journal Bioscience and Bioengineering, v. 110, n. 3, p. 246-251, 2010. http://dx.doi.org/10.1016/j.jbiosc.2010.03.015

JOHN, R. P.; NAMPOOTHIRI, K.M.; PANDEY, A. Polyurethane foam as an inert carrier for the production of L (+)lactic acid by Lactobacillus casei under solid-state fermentation. Letters Applied Microbiology, v. 44, n. 1, p. 582587, 2007. http://dx.doi.org/10.1111/j.1472-765X.2007.02137.x

KASANA, R.C.; SALWAN, R.; YADAV, S.K. Microbial proteases: Detection, production, and genetic improvement. Critical Reviews in Microbiology, v. 37, n. 3, p. 262-276, 2011. http://dx.doi.org/10.3109/1040841X.2011.57702

LADEIRA, S. A.; ANDRADE, M. V. V.; DELATORRE, A. B.; PEREZ, V. H.; MARTINS, M. L. L. Utilização de resíduos agroindustriais para a produção de proteases pelo termofílico Bacillus sp. em fermentação submersa: otimização do meio de cultura usando a técnica de planejamento experimental. Química Nova, v. 33, n. 2, p. 324-328, 2010. http://dx.doi.org/10.1590/S0100-40422010000200018

MAHANTA, N.; GUPTA, A.; KHARE, S.K. Production of protease and lipase by solvent tolerant Pseudomonas aeruginosa PseA in solid-state fermentation using Jatropha curcas seed cake as substrate, Bioresource Technology, v. 99, n. 6, p. 1729-1735, 2008. http://dx.doi.org/10.1016/j.biortech.2007.03.046 
NASCIMENTO, W. C. A.; MARTINS, M. L. L. Produção de proteases por Bacillus sp. SMIA-2 crescido em soro de leite e água de maceração de milho e compatibilidade com detergentes comerciais. Ciência e Tecnologia de Alimentos, v. 26, n. 3, p. 582-588, 2006. http://dx.doi.org/10.1590/S0101-20612006000300016

PILLAI, P.; MANDGE, S.; ARCHANA, G. Statistical optimization of production and tannery applications of a keratinolytic serine protease from Bacillus subtilis P13, Process Biochemistry, v. 46, n. 5, p. 1110-1117, 2011. http://dx.doi.org/10.1016/j.procbio.2011.01.030

SECADES, P.; GUIJARRO, J. A. Purification and characterization of an extracellular protease from the fish pathogen Yersinia ruckery and effect of culture conditions on production. Applied Environmental Microbiology, v. 65, n. 9, p. 3969-3979, 1999.

SHINGHANIA, R. R.; PATE, A. K.; SOCCOL, C. R.; PANDEY, A. Recent advances in solid-state fermentation. Biochemical Engineering Journal, v. 44, n. 1, p. 13-18, 2009. http://dx.doi.org/10.1016/j.bej.2008.10.019

SILVA, A.R.Z. Desenvolvimento de bioprocessos para a produção de fitase por Aspergillus niger em fermentação no estado sólido utilizando subprodutos agrícolas para aplicação como aditivo na alimentação de aves e suínos. 2002. 96f. Dissertação (Mestrado em Tecnologia de Alimentos) - Setor de Tecnologia - Universidade Federal do Paraná. Curitiba, 2002.

SILVA, G. A. B.; ALMEIDA, W. E. S.; MARTINS, E. S. Produção e caracterização de proteases obtidas por Glicocladium verticilloides através da fermentação em estado sólido de subprodutos agroindustriais. Revista Brasileira de Tecnologia Agroindustrial, v. 3, n.1, p. 28-41, 2009. http://dx.doi.org/10.3895/S1981-36862009000100003

SOCCOL, C. R.; VANDENBERGHE, L. P. S. Overview of applied solid-state fermentation in Brazil. Biochemical Engineering Journal, v. 13, n. 2, p. 205-218, 2003. http://dx.doi.org/10.1016/S1369-703X(02)00133-X

THYS, R. C. S. Produção, caracterização, purificação e aplicação de uma protease produzida pelo microrganismo Microbacterium sp. kr10. Porto Alegre, 2004. 114f. Dissertação (Mestrado em Microbiologia Agrícola e do Ambiente) - Faculdade de Agronomia - Universidade Federal do Rio Grande do Sul.

Submetido em 02 nov. 2011, Aceito para publicação em 28 set. 2012. 